\title{
The Subventricular Zone Continues to Generate Corpus Callosum and Rostral Migratory Stream Astroglia in Normal Adult Mice
}

\author{
Jiho Sohn, ${ }^{1}$ Lori Orosco, ${ }^{1}$ CFuzheng Guo, ${ }^{1}$ Seung-Hyuk Chung, ${ }^{2}$ Peter Bannerman, ${ }^{1}$ Emily Mills Ko, ${ }^{1}$ Kostas Zarbalis, ${ }^{1}$ \\ Wenbin Deng, ${ }^{1}$ and ${ }^{\circ}$ David Pleasure ${ }^{1}$ \\ ${ }^{1}$ Institute for Pediatric Regenerative Medicine, University of California, Davis, School of Medicine, Sacramento, California 95817, and ${ }^{2}$ Department of Oral \\ Biology, University of Illinois at Chicago, Chicago, Illinois 60612
}

\begin{abstract}
Astrocytes are the most abundant cells in the CNS, and have many essential functions, including maintenance of blood-brain barrier integrity, and CNS water, ion, and glutamate homeostasis. Mammalian astrogliogenesis has generally been considered to be completed soon after birth, and to be reactivated in later life only under pathological circumstances. Here, by using genetic fate-mapping, we demonstrate that new corpus callosum astrocytes are continuously generated from nestin ${ }^{+}$subventricular zone (SVZ) neural progenitor cells (NPCs) in normal adult mice. These nestin fate-mapped corpus callosum astrocytes are uniformly postmitotic, express glutamate receptors, and form aquaporin $-4^{+}$perivascular endfeet. The entry of new astrocytes from the SVZ into the corpus callosum appears to be balanced by astroglial apoptosis, because overall numbers of corpus callosum astrocytes remain constant during normal adulthood. Nestin fate-mapped astrocytes also flow anteriorly from the SVZ in association with the rostral migratory stream, but do not penetrate into the deeper layers of the olfactory bulb. Production of new astrocytes from nestin ${ }^{+}$NPCs is absent in the normal adult cortex, striatum, and spinal cord. Our study is the first to demonstrate ongoing SVZ astrogliogenesis in the normal adult mammalian forebrain.
\end{abstract}

Key words: astroglia; corpus callosum; genetic fate-mapping; neural progenitor cells; rostral migratory stream; subventricular zone

\section{Introduction}

Brain size quadruples and brain astroglial numbers increase 6- to 8 -fold in normal mice and rats during the first 3 postnatal weeks (Agrawal et al., 1968; Bandeira et al., 2009; Chuang et al., 2011). There are two known forebrain origins for this rapid postnatal astrogliogenesis: (1) subventricular zone (SVZ) neural progenitor cells (NPCs) give rise to both corpus callosum and cortex astrocytes, and (2) cortical astrocytes expand themselves by symmetric divisions (Levison et al., 1993; Suzuki and Goldman, 2003; Ge et al., 2012). It has been reported, however, that, in normal circumstances, both of these astroglial recruitment mechanisms cease at the conclusion of this initial phase of rapid forebrain growth (Ling and Leblond, 1973; Sauvageot and Stiles, 2002; Ge et al., 2012), and are reactivated in adults only under pathological circumstances, for example after neural trauma (Buffo et al.,

\footnotetext{
Received Aug. 18, 2014; revised Dec. 15, 2014; accepted Jan. 14, 2015.

Author contributions: J.S., L.O., F.G., S.-H.C., P.B., E.M.K., K.Z., W.D., and D.P. designed research; J.S., L.O., F.G., and S.-H.C. performed research; S.-H.C. and P.B. contributed unpublished reagents/analytic tools; J.S., L.O., F.G., S.-H.C., P.B., E.M.K., K.Z., W.D., and D.P. analyzed data; J.S. and D.P. wrote the paper.

This work was supported by the Department of Defense (W81XWH-12-1-0566), Shriners Hospitals for Children, and the National Multiple Sclerosis Society (RG 5252-A-6).

The authors declare no competing financial interests.

Correspondence should be addressed to Dr David Pleasure, Institute for Pediatric Regenerative Medicine, UC Davis School of Medicine, c/o Shriners Hospital, 2425 Stockton Boulevard, Sacramento, CA 95817. E-mail: david.pleasure@ucdmc.ucdavis.edu.

DOI:10.1523/JNEUROSCI.3454-14.2015

Copyright $\odot 2015$ the authors $\quad 0270-6474 / 15 / 353756-08 \$ 15.00 / 0$
}

2008; Benner et al., 2013). In support of this conclusion, mitotically cycling astrocytes are rarely seen outside the forebrain neurogenic niches in normal adults (Buffo et al., 2008; Molofsky et al., 2012). But in one early study, although a $2 \mathrm{~h}$ systemic pulse of ${ }^{3} \mathrm{H}$-thymidine failed to label corpus callosum astrocytes in normal adult mice, labeled corpus callosum astroglial nuclei were detected by autoradiography after $30 \mathrm{~d}$ of continuous systemic ${ }^{3} \mathrm{H}$-thymidine administration (McCarthy and Leblond, 1988). The authors concluded that immature cells residing in the corpus callosum continued to divide and to give rise to astrocytes, but did not consider the alternate possibility that those labeled astrocytes had instead been generated from SVZ NPCs.

We have now reevaluated normal adult SVZ astrogliogenesis by genetic fate-mapping in mice carrying tamoxifen-inducible nestin-cre (nestin-creER ${ }^{\mathrm{T} 2}$ ) transgene and Rosa26R-STOPEYFP recombination marker (Lagace et al., 2007). Our results indicate that nestin ${ }^{+}$SVZ NPCs continue to generate corpus callosum astrocytes during normal adulthood, at a rate that gradually declines with advancing age. Together with our observations that: (1) overall numbers of astrocytes remain constant, and (2) astroglial apoptosis occurs in the normal adult corpus callosum, our data support the concept that there is slow, continuous turnover of astrocytes in the normal adult corpus callosum, with replacement by new astrocytes generated from nestin ${ }^{+}$SVZ NPCs. In addition, the SVZ continuously exports astrocytes to the rostral migratory stream (RMS). Unlike in the corpus callo- 
A

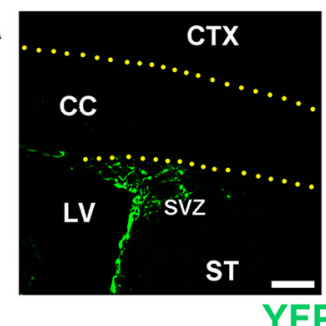

B

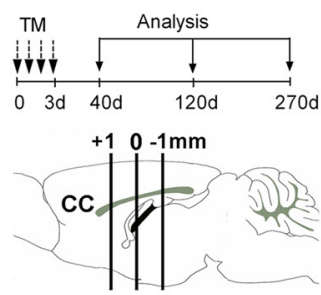

YFP DAPI (40d)
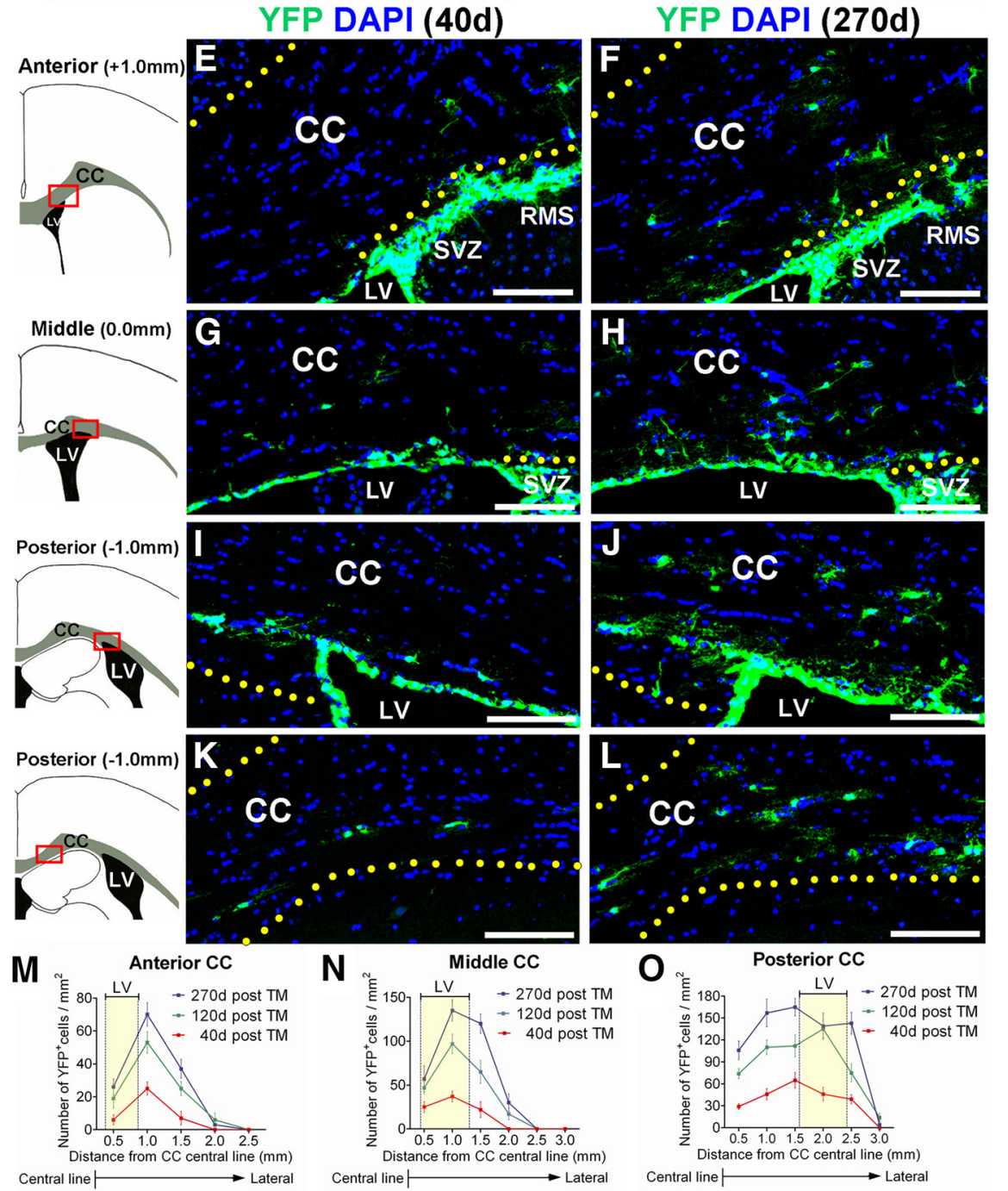

Figure 1. Density and distribution analyses of nestin fate-mapped cells in the adult corpus callosum. $A$, Coronal brain section of 3-month-old NCER mice immunostained for EYFP $1 \mathrm{~d}$ after completion of a series of TM injections (i.p., $180 \mathrm{mg} / \mathrm{kg}$ body weight, daily for 4 consecutive days), showing EYFP ${ }^{+}$cells are restricted to the SVZ. B, C, Experimental design: $\boldsymbol{B}, 3$-month-old NCER mice received TM injections and were then killed at later time points $(40,120$ or $270 \mathrm{~d})$. C, Immunohistological analysis was done on coronal brain sections at $1.0 \mathrm{~mm}$ anterior, $0.0 \mathrm{~mm}$ and $1.0 \mathrm{~mm}$ posterior to the bregma (anterior, middle, and posterior corpus callosum, respectively). $\boldsymbol{D}$, With increasing time post-TM injection, the density of EYFP ${ }^{+}$cells increased in all 3 anterior-posterior regions of the corpus callosum (anterior CC: ${ }^{*} p<0.01$ vs $40 \mathrm{~d},{ }^{* *} p<0.005$ vs $40 \mathrm{~d}$, \#p $<0.05$ vs $120 \mathrm{~d}$; middleCC: ${ }^{* *} p<0.005$ vs $40 \mathrm{~d}$, \#\#p $<0.01$ vs $120 \mathrm{~d}$; posterior CC: ${ }^{* *} p<$ 0.005 vs $40 \mathrm{~d}$, \#\#p $<0.01$ vs $120 \mathrm{~d}$ ). $\boldsymbol{E}-\boldsymbol{L}$, Images of EYFP ${ }^{+}$cells in anterior $(\boldsymbol{E}, \boldsymbol{F})$, middle $(\boldsymbol{G}, \boldsymbol{H})$, and posterior $(\boldsymbol{I}-\boldsymbol{L})$ corpus callosum at 40 and $270 \mathrm{~d}$ after TM. The corpus callosum is demarcated by dotted lines. Rectangles in schematic drawings on the left mark the location of the images shown on the right. $\boldsymbol{M}-\mathbf{0}$, Mediolateral distributions of EYFP ${ }^{+}$cells in anterior $(\boldsymbol{M})$, middle $(\boldsymbol{N})$, and posterior $(\boldsymbol{O})$ corpus callosum. Note regional differences in mediolateral distributions of EYFP ${ }^{+}$cells in different anterior-posterior regions of the corpus callosum. In the posterior corpus callosum ( $\mathbf{O})$, EYFP ${ }^{+}$cells were more widely distributed whereas in more anterior segments $(\boldsymbol{M}, \boldsymbol{N})$ of the corpus callosum, $\mathrm{EYFP}^{+}$cells were largely confined to the area close to the SVZ. Yellow areas in the graphs indicate mediolateral locations of the lateral ventricles. CC, Corpus callosum; (TX, cortex; LV, lateral ventricle; ST, striatum. Scale bars, $100 \mu \mathrm{m}$. Results are mean \pm SEM ( $n=3-4$ brains).

sum and the RMS, the SVZ does not give rise to new cortical or striatal astrocytes in normal adults. Moreover, no evidence of NPC-derived astrogliogenesis is detectable in the normal adult spinal cord.

\section{Materials and Methods}

Animals. C57BL/6 nestin-Cre-ER ${ }^{\mathrm{T} 2}$ transgenic mice (Lagace et al., 2007) were crossed to C57BL/6 Rosa26R-STOP-EYFP reporter transgenic mice (The Jackson Laboratory; Srinivas et al., 2001) to yield nestin-creER ${ }^{\mathrm{T} 2} / \mathrm{R} 26 \mathrm{R}-\mathrm{EYFP}$ (NCER) double-transgenic mice. The nestinCre-ER ${ }^{\mathrm{T} 2}$ construct used in the $\mathrm{C} 57 \mathrm{BL} / 6$ nestinCre-ER ${ }^{\mathrm{T} 2}$ transgenic mice has a second intronic element that enhances nestin expression specifically in NPCs, but not in endothelial cells (Zimmerman et al., 1994; Lagace et al., 2007). GFAP:GFP transgenic mice [FVB/N$\operatorname{Tg}$ (GFAPGFP)14Mes/J; Zhuo et al., 1997] were purchased from The Jackson Laboratory (stock no. 003257). GFAP:GFP transgenic mice were then crossed with C57BL/6 wildtype mice (obtained initially from the Jackson Laboratory) for $>7$ generations to produce GFAP:GFP transgenic mice on a C57BL/6 background. Both males and females were used in this study. All protocols used in these studies were preapproved by the UC Davis IACUC.

Tamoxifen administration. To genetically label nestin ${ }^{+}$SVZ NPCs, 3 month postnatal NCER mice were given intraperitoneal (i.p.) tamoxifen (TM) dissolved in 10\% EtOH/90\% sunflower oil (v/v) at $180 \mathrm{mg} / \mathrm{kg} / \mathrm{d}$ for 4 consecutive days. Five days of TM at this dose had previously been reported to induce maximal genetic recombination with minimal mortality (Lagace et al., 2007), but we found that reducing administration to $4 \mathrm{~d}$ further lowered lethality without compromising recombination efficacy in 3-month-old NCER mice.

Immunohistochemistry and quantification. At the termination of experiments, the mice were anesthetized with ketamine $(150 \mathrm{mg} / \mathrm{kg}$ body weight, i.p.) and xylazine $(16 \mathrm{mg} / \mathrm{kg}$ body weight, i.p.), and transcardially perfused with PBS, followed by $4 \%$ paraformaldehyde (PFA) in PBS. Brain tissues were isolated and postfixed with $4 \%$ PFA in PBS overnight at $4^{\circ} \mathrm{C}$. Tissues were cryoprotected, sectioned and further immunostained as previously described (Sohn et al., 2012). TUNEL (terminal deoxynucleotidyl transferase dUTP nick end labeling) staining was performed by using DeadEnd TUNEL assay kit (Promega) following the manufacturer's instructions. Primary antibodies were as follows: anti-YFP/GFP (1:500, Abcam, Ab13970), anti-GFAP (1:500, SigmaAldrich G3893; Dako, Z0334), anti-Nestin (1: 100, Santa Cruz Biotechnology sc-21249), antivimentin (1:500, Abcam, ab8979), anti-Ki67 (1:500, Abcam, ab15580), anti-EAAT1 (1:100, Abcam, Ab416), anti-EAAT2 (1:100, Abcam, Ab41621), anti-aquaporin-4 (1:50, Santa Cruz Biotechnology, Sc-20812), anti-DCX (1:50, Santa Cruz Biotechnology, Sc-8066), antiSox10 (1:50, Santa Cruz Biotechnology, Sc17342), and anti-PECAM (1:50, Santa Cruz Biotechnology, Sc-18916). All fluorescent images were captured by laser scanning confocal microscopy (Nikon, C1).

For quantification (Figs. 1-4), cell counting in anterior, middle, and posterior corpus callosum was performed in coronal sections $+1.0 \mathrm{~mm}$, $0.0 \mathrm{~mm},-1.0 \mathrm{~mm}$ with respect to the bregma, respectively. At each 
coordinate, almost the entire corpus callosal area spanning $5.0 \mathrm{~mm}$ of mediolateral distance for the anterior and middle corpus callosum, and $6.0 \mathrm{~mm}$ for the posterior corpus callosum was analyzed. In Figure $1 M-O$, cell density was determined within each segment $(500 \mu \mathrm{m})$ of the corpus callosum relative to the distance from the corpus callosal central point, and in Figures $1 D, 3 E, F$, and $4 B$, the total cell numbers were divided by the total area of the corpus callosum examined. For quantification shown in Fig. $5 B, C$, coronal brain sections $+1.0 \mathrm{~mm}$ to the bregma were used, which displayed the mediolateral extension of the posterior RMS from the anterior SVZ. In Fig. 5B, the distance $(\mu \mathrm{m})$ from SVZ dorsal corner to the most laterally positioned $\mathrm{EYFP}^{+} / \mathrm{GFAP}^{+}$cells in the posterior RMS was measured. For each marker, at least 10 sections were analyzed, and cells were identified by their DAPI labeled nuclei.

Extrapolation of net daily addition of $\mathrm{YFP}^{+}$/ GFAP $^{+}$astrocytes. To estimate net daily addition of fate-mapped corpus callosum astrocytes (Fig. 4D), net increases in numbers of $\mathrm{YFP}^{+} / \mathrm{GFAP}^{+}$cells in the corpus callosum during the time-intervals between 0 and 40, 40 and 120 , and 120 and $270 \mathrm{~d}$ post-TM were divided by the number of days spanning the two TM time-points (i.e., 40, 80, $150 \mathrm{~d}$, respectively). Each value in the graph represents the average net daily addition of $\mathrm{YFP}^{+} / \mathrm{GFAP}^{+}$astrocytes between the two post-TM time intervals.

Statistical analyses. Data are expressed as mean \pm SEM. Statistical analyses were performed by ANOVA with Newman-Keuls post hoc testing (using GraphPad Prism 5).

\section{Results}

Nestin ${ }^{+}$SVZ NPCs give rise to astrocytes in the normal adult corpus callosum

To examine SVZ-derived astrogliogenesis in the corpus callosum during normal adulthood, we fate-mapped nestin $^{+}$ NPCs in the SVZ by administering TM to 3-month-old adult NCER mice. In mice killed $1 \mathrm{~d}$ after completing a series of TM administration (i.e., IP, daily injection for 4 consecutive days), fate-mapped (i.e., $\mathrm{EYFP}^{+}$) cells were restricted to the SVZ, and were not detected in neighboring corpus callosum, cortex, or striatum (Fig. 1A), confirming a lack of ectopic recombination by nestin-creER ${ }^{\mathrm{T} 2}$ in these forebrain structures. We then mapped the progeny of $\mathrm{EYFP}^{+}$cells at later time-points (40, 120 and $270 \mathrm{~d}$ post-TM) (Fig. 1B). Immunohistochemical analyses were performed in coronal brain sections at three different anterior-posterior coordinates: $1.0 \mathrm{~mm}$ anterior, $0.0 \mathrm{~mm}$, and $1.0 \mathrm{~mm}$ posterior to the bregma (designated as anterior, middle, and posterior corpus callosum, respectively; Fig. $1 C$ ). With increasing time post-TM administration, increasing numbers of $\mathrm{EYFP}^{+}$cells were present in all three examined positions of the corpus callosum (Fig. 1D-L). The number of these $\mathrm{EYFP}^{+}$cells was highest in the posterior and lowest in the anterior corpus callosum. We also quantified
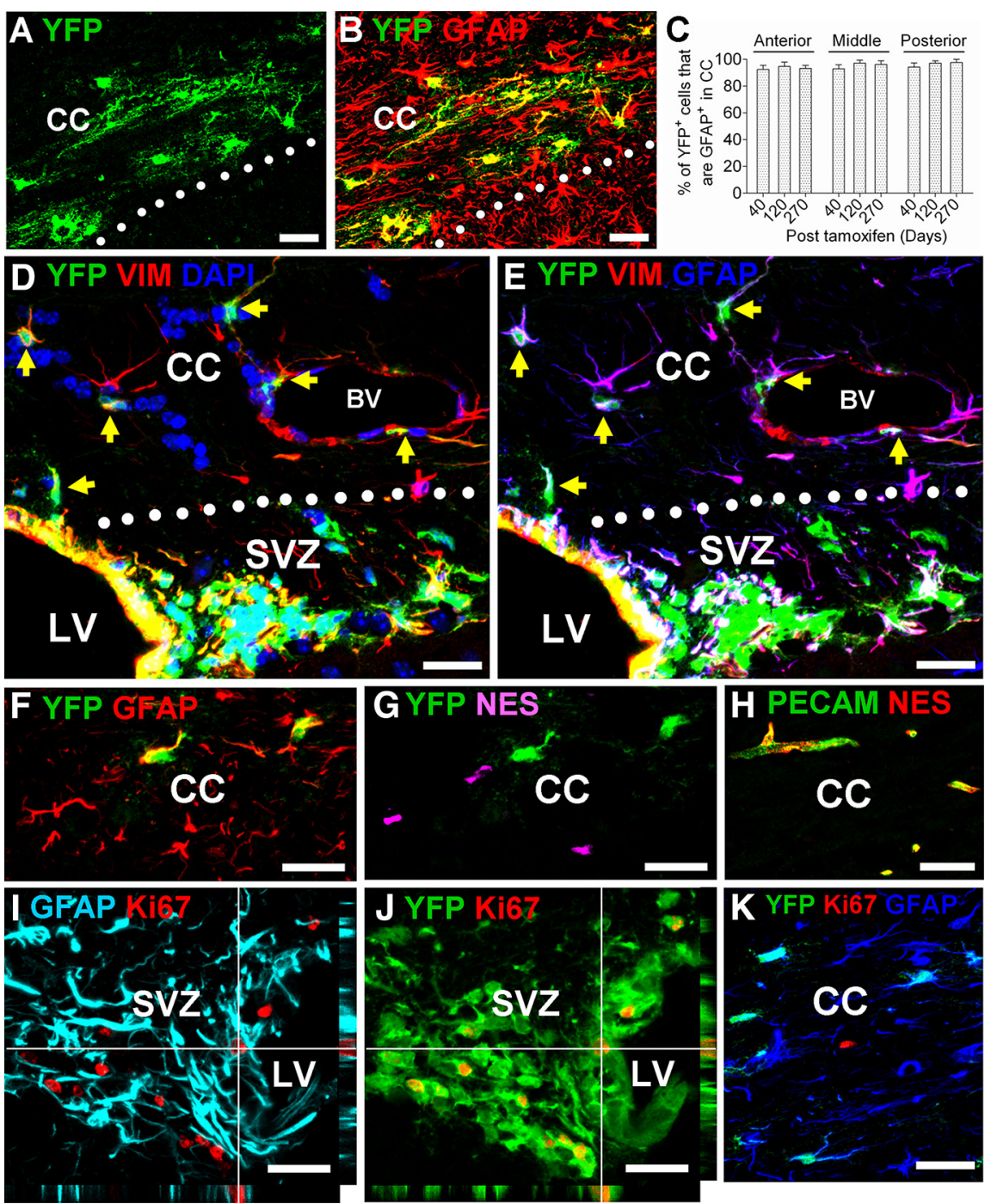
(in detected in the corpus callosum, $\boldsymbol{F}, \mathbf{G}$, EYFP ${ }^{+} / \mathrm{GFAP}^{+}$cells in the corpus callosum do not express nestin. $\boldsymbol{H}$, Colocalization of nestin and PECAM (i.e., endothelial cells) expressions in the corpus callosum of adult wild-type mice. $I, J$, Orthogonal images of EYFP ${ }^{+} / \mathrm{GFAP}^{+} /$ $\mathrm{Ki}^{+}{ }^{+}$cell in the SVZ at $120 \mathrm{~d}$ post-TM, showing the presence of a fate-mapped mitotic astroglial cell (i.e., presumably type B cell). $\boldsymbol{K}$, $\mathrm{EYFP}^{+} / \mathrm{GFAP}^{+}$astrocytes in the corpus callosum do not proliferate. BV, Blood vessel; $C$, corpus callosum; LV, lateral ventricle. Dotted lines in $(\boldsymbol{A}, \boldsymbol{B}, \boldsymbol{D}, \boldsymbol{E})$ demarcate the corpus callosum. Scale bars, $25 \mu \mathrm{m}$. Results are mean \pm SEM ( $n=3-4$ brains).

mediolateral distributions of $\mathrm{EYFP}^{+}$cells to determine the extents of their migration with respect to the SVZ (Fig. 1M$O)$. In the anterior and middle corpus callosum, most $\mathrm{EYFP}^{+}$ cells were located in close proximity to the SVZ (Fig. 1E$H, M, N)$, but in the posterior corpus callosum, $\mathrm{EYFP}^{+}$cells were more widely distributed (Fig. $1 I-L, O$ ), including EYFP ${ }^{+}$ cells in the medial corpus callosum, relatively far from the SVZ (Fig. $1 K, L, O$ ). The vast majority of EYFP ${ }^{+}$cells (i.e., 93-97\%) in the corpus callosum were $\mathrm{GFAP}^{+}$(Fig. $2 A-C$ ), the remainder being $\mathrm{GFAP}^{-} / \mathrm{Sox}_{10} 0^{+}$oligodendroglial lineage cells or doublecortin $(\mathrm{DCX})^{+}$neuroblasts (data not shown). We did not detect fate-mapped endothelial cells (Fig. $3 A-D$ ) or microglia (data not shown). These results indicated ongoing recruitment of astrocytes from the SVZ to the corpus callosum during normal adulthood. 

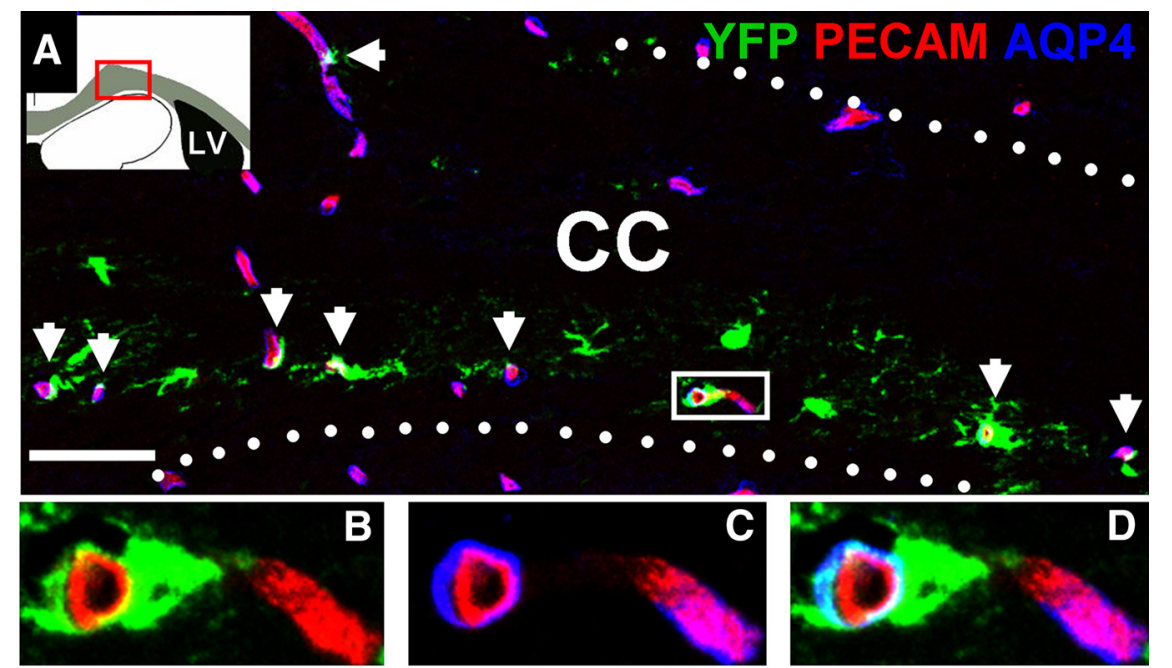

E

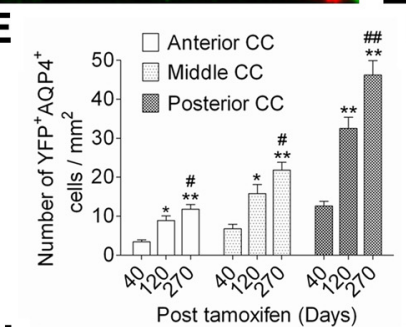

H Post tamoxifen (Days)
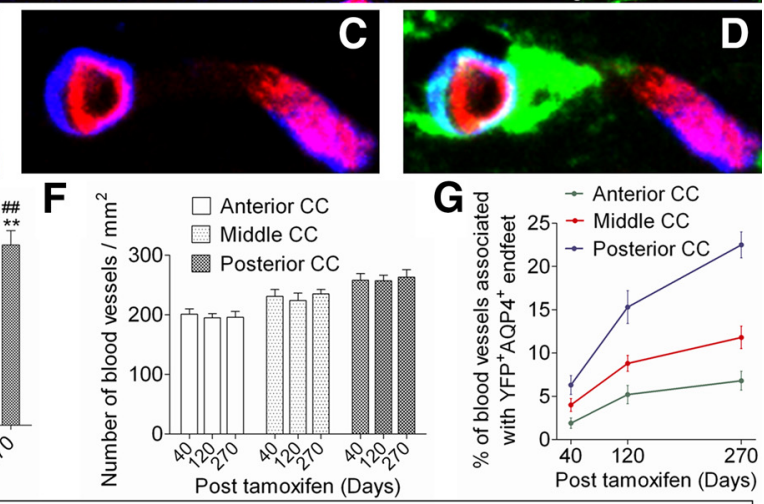

$\mathbf{G}_{\text {욤 }}$

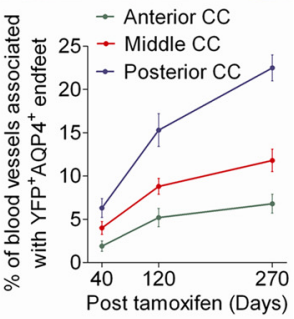

YFP EAAT1 GFAP
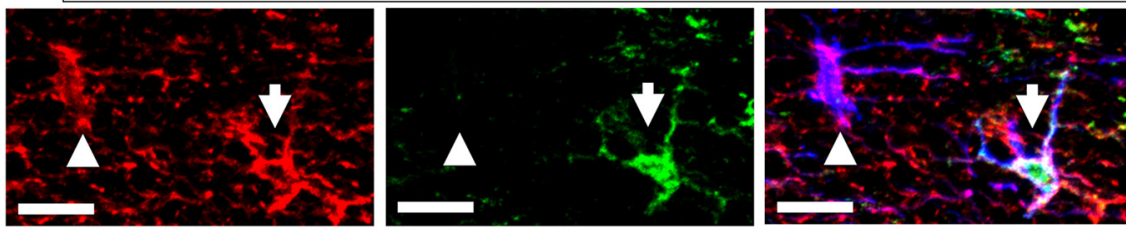

I
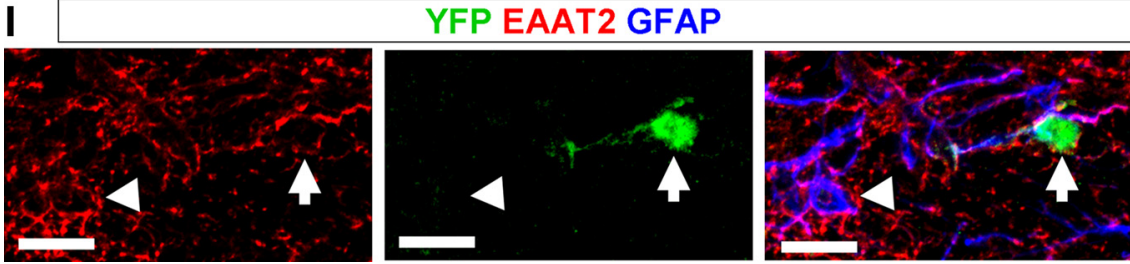

Figure 3. Formation of perivascular endfeet and glutamate transporters by nestin fate-mapped astrocytes in the adult corpus callosum. A, Low-magnification image of the posterior corpus callosum at $270 \mathrm{~d}$ post-TM immunostained for EYFP, GFAP, and $A Q P 4$. A red rectangle in the schematic drawing shows the location of the low-magnification image. Arrows indicate the contacts between EYFP ${ }^{+} / \mathrm{AQP}^{+}{ }^{+}$astrocytic endfeet and PECAM ${ }^{+}$endothelial cells. Dotted lines demarcate the corpus callosum. $\boldsymbol{B}-\boldsymbol{D}$, Higher magnifications of the area marked by the white rectangle in $\boldsymbol{A}$, showing EYFP ${ }^{+} / \mathrm{AQP}^{+}{ }^{+}$astrocytic endfeet completely enwrapping a PECAM ${ }^{+}$blood vessel. $\boldsymbol{E}$, The density of EYFP ${ }^{+} / \mathrm{AQP4}{ }^{+}$perivascular astrocytes in the adult corpus callosum increased with increasing time after TM and toward more posterior regions of the corpus callosum (anterior CC: ${ }^{*} p<0.01$ vs $40 \mathrm{~d}$, ${ }^{* *} p<0.005$ vs $40 \mathrm{~d}$, \#p $<0.05$ vs $120 \mathrm{~d}$; middle CC: ${ }^{*} p<0.01$ vs $40 \mathrm{~d}$, ${ }^{* *} p<0.005$ vs $40 \mathrm{~d}$, $\# p<0.05$ vs $120 \mathrm{~d}$; posterior CC: ${ }^{* *} p<0.005$ vs $40 \mathrm{~d}$, \#\#p $<0.01$ vs $120 \mathrm{~d}$ ). $\boldsymbol{F}$, The density of PECAM ${ }^{+}$blood vessels in different anterior-posterior regions of the adult corpus callosum. $\mathbf{G}$, The percentages of PECAM ${ }^{+}$blood vessels that were in contact with EYFP ${ }^{+} / \mathrm{AQP}^{+}{ }^{+}$endfeet in anterior, middle, and posterior corpus callosum with increasing time after TM. Note that at $270 \mathrm{~d}$ after TM, $22.5 \%$ of total blood vessels in the posterior corpus callosum were associated with EYFP ${ }^{+} / \mathrm{AQP} 4{ }^{+}$astrocytic endfeet. $\boldsymbol{H}, \boldsymbol{I}$, Both EYFP ${ }^{-} / \mathrm{GFAP}^{+}$(arrowheads) and $\mathrm{EYFP}^{+} / \mathrm{GFAP}^{+}$(arrows) astrocytes in the corpus callosum expressed excitatory amino acid transporters 1 (EAAT1; $\boldsymbol{H}$ ) and EAAT2 (I), astrocyte-specific glutamate transporters. CC, Corpus callosum. Scale bars: $\boldsymbol{A}, 100 \mu \mathrm{m} ; \boldsymbol{H}, \boldsymbol{I}, 15 \mu \mathrm{m}$. Results are mean \pm SEM ( $n=3-4$ brains).

Nestin fate-mapped astrocytes in the normal adult corpus callosum do not retain immature astroglial characteristics We further examined whether these newly recruited corpus callosum $\mathrm{GFAP}^{+}$cells display an immature astroglial phenotype. Vimentin is expressed by radial glia and immature astrocytes in early development and also by mature astrocytes in adults, preceding GFAP expression during normal astroglial maturation
(Schnitzer et al., 1981; Pixley and de Vellis, 1984; Galou et al., 1996). Thus, if $\mathrm{EYFP}^{+} /$vimentin $^{+} / \mathrm{GFAP}^{-}$cells were present in the corpus callosum, they would presumably represent immature astrocytes. All corpus callosum $\mathrm{EYFP}^{+} /$ $\mathrm{GFAP}^{+}$cells coexpressed vimentin, and we did not detect corpus callosum $\mathrm{EYFP}^{+} /$ vimentin ${ }^{+} / \mathrm{GFAP}^{-}$cells (Fig. $2 \mathrm{D}, \mathrm{E}$ ). Nestin is another immature astroglial marker during early development, but it is not expressed by normal mature astrocytes (Kálmán and Ajtai, 2001; Sild and Ruthazer, 2011). None of the $\mathrm{EYFP}^{+} / \mathrm{GFAP}^{+}$ cells in the corpus callosum we examined expressed immunoreactive nestin (Fig. $2 F, G)$. We observed abundant nestin cells in the adult corpus callosum, but they were PECAM ${ }^{+}$endothelial cells (Fig $2 \mathrm{H}$ ). Moreover, $\mathrm{EYFP}^{+} / \mathrm{GFAP}^{+}$cells in the corpus callosum were uniformly Ki67 (Fig. 2K), whereas proliferating fatemapped astroglial cells (i.e., $\mathrm{Ki} 7^{+} / \mathrm{EYFP}^{+} /$ $\mathrm{GFAP}^{+}$cells) were detectable in the SVZ (Fig. 2I,J). Altogether, our data indicate that the fate-mapped $\mathrm{GFAP}^{+}$cells in the adult corpus callosum are mature, postmitotic astrocytes, and that these fate-mapped astrocytes are derived solely from the SVZ without further expansion by proliferation in the corpus callosum.

Nestin fate-mapped astrocytes in the normal adult corpus callosum display perivascular phenotype and express glutamate transporters

Some $\mathrm{EYFP}^{+}$cells in the corpus callosum formed aquaporin-4 (AQP-4) ${ }^{+}$perivascular contacts (Nielsen et al., 1997) with PECAM $^{+}$blood vessels (Fig. 3A-D). With increasing time post-TM, the numbers of the corpus callosum $\mathrm{EYFP}^{+} / \mathrm{AQP}-4^{+}$astrocytes progressively increased whereas the total numbers of corpus callosum blood vessels remained constant (Fig. 3E$G)$. Virtually all of the EYFP ${ }^{+}$astrocytes in the corpus callosum had the "star-like" shape and dense $\mathrm{GFAP}^{+}$glial filaments typical of white matter fibrous astrocytes (Molofsky et al., 2012), and expressed the astroglial-specific excitatory amino acid transporter EAAT1 (GLAST) and EAAT2 (GLT-1; Rothstein et al., 1994; Chaudhry et al., 1995; Fig. 3 H,I). Notably, immunoreactive intensities for EAAT1 and EAAT2 were comparable between SVZ-derived (i.e., $\mathrm{EYFP}^{+} / \mathrm{GFAP}^{+}$) and preexisting (i.e., $\mathrm{EYFP}^{-} / \mathrm{GFAP}^{+}$) astrocytes.

Astroglial turnover in the normal adult corpus callosum The total numbers of corpus callosum astrocytes in the interval between 3 and 12 months of age did not alter, as determined by quantification of GFAP:GFP ${ }^{+}$cells using GFAP: 
GFP transgenic mice (Fig. 4A,B). Furthermore, albeit at low-frequency, we were able to detect astroglial apoptosis by TUNEL assay in the adult corpus callosum (Fig. 4C). Together, our results indicated that astrocyte turnover takes place in the normal adult corpus callosum, with continuous provision of new astrocytes from the SVZ. As shown in Fig. $4 D$, addition of new astrocytes to the corpus callosum was more rapid in young than old mice, and in the posterior than anterior segment of the corpus callosum.

\section{Robust production of RMS astrocytes from nestin ${ }^{+}$SVZ NPCs during normal adulthood}

To explore the possibility that new astrocytes also transit from the SVZ to the RMS, we analyzed the appearance of $\mathrm{EYFP}^{+} / \mathrm{GFAP}^{+}$astrocytes at posterior (Fig. 5A-E) and anterior (Fig. 5F-I) levels of the RMS as a function of time post-TM. For posterior RMS (pRMS), we used coronal sections at $1.0 \mathrm{~mm}$ anterior to the bregma to examine the mediolateral stream of the pRMS that extends from the anterior SVZ. At early time-points post-TM (i.e., $3 \mathrm{~d}$ : not shown, 7 d: Fig. $5 D$ ), EYFP ${ }^{+} / \mathrm{GFAP}^{+}$ astrocytes were largely restricted to the SVZ, with a few present in the pRMS. With increasing time post-TM, there was a lateral stream of EYFP ${ }^{+}$cells from the SVZ toward the pRMS (Fig. $5 E ; 120 \mathrm{~d}$ post-TM), and an increase in both the lateral migration (Fig. $5 B$ ) and the density (Fig. 5C) of $\mathrm{EYFP}^{+} /$ $\mathrm{GFAP}^{+}$astrocytes within the pRMS. For anterior RMS (aRMS), we analyzed both coronal (Fig. $5 H, I$ ) and sagittal sections (Fig. $5 F, G$ ) at $2.5 \mathrm{~mm}$ anterior to the bregma and $0.8 \mathrm{~mm}$ lateral to the midline, respectively. At 3 d post-TM, a few EYFP ${ }^{+}$ cells were present in the aRMS, some of which were also GFAP ${ }^{+}$(Fig. 5F). By $120 \mathrm{~d}$ post-TM, a robust stream of $\mathrm{EYFP}^{+}$cells had become associated with the aRMS (Fig. $5 G)$. Most of these $\mathrm{EYFP}^{+}$cells were DCX ${ }^{+}$ neuroblasts (Fig. $5 H$ ), but the aRMS also contained a substantial number of $\mathrm{EYFP}^{+} /$ $\mathrm{GFAP}^{+}$astrocytes, as seen in both sagittal (Fig. 5G) and coronal (Fig. 5I) sections. Whereas there were numerous fate-mapped $\mathrm{DCX}^{+}$neuroblasts and neurons in the granule cell layer (GCL) of the olfactory bulb (data not shown), $\mathrm{EYFP}^{+} / \mathrm{GFAP}^{+}$ cells, though migrating to the anterior RMS within the olfactory bulb (Fig. $5 J, K$ ), failed to advance into the olfactory bulb GCL (Fig. 5L).

Given prior reports of the presence of $\mathrm{GFAP}^{+}$astroglial precursors in the RMS (Alonso et al., 2008; Alvarez-Buylla et al.,
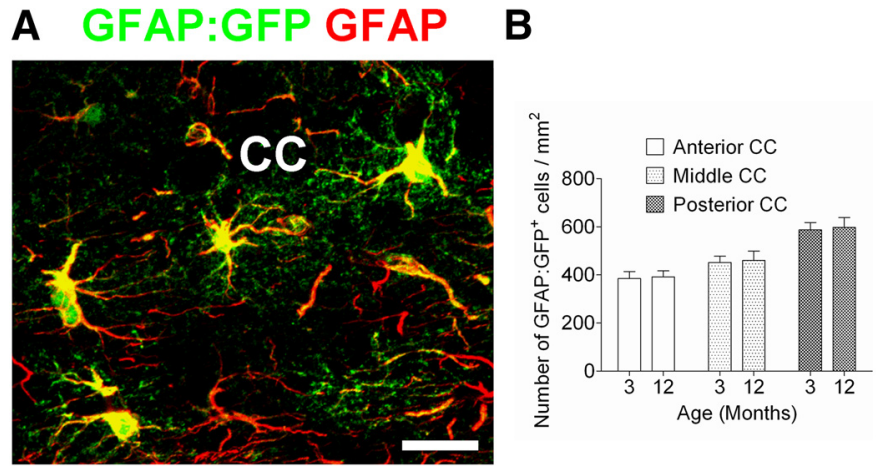

\section{TUNEL GFAP DAPI D}
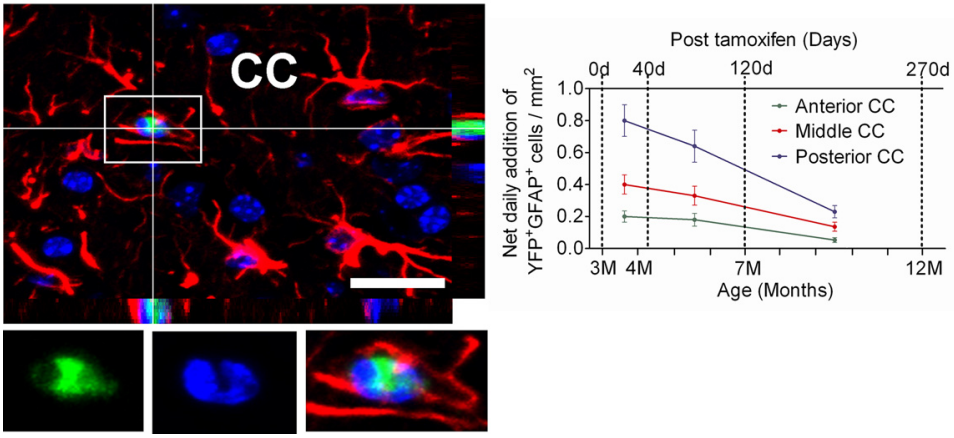

Figure 4. Astrocyte turnover in the adult corpus callosum. $\boldsymbol{A}$, Image of adult GFAP:GFP mouse corpus callosum immunostained for GFP and GFAP showing colocalization of GFAP:GFP and GFAP. B, Quantification of total numbers of GFAP:GFP ${ }^{+}$astrocytes in the adult corpus callosum. $C$, Orthogonal view of a TUNEL ${ }^{+} / \mathrm{GFAP}^{+} / \mathrm{DAPI}^{+}$cell in the adult corpus callosum. Insets below are the magnified images of the area outlined by the rectangle. Note convoluted nucleus with cavitation, a feature of early apoptosis (Johnson et al., 2000). D, Calculated net daily addition of EYFP ${ }^{+} /$GFAP $^{+}$astrocytes in the adult corpus callosum. CC: corpus callosum. Scale bars, $20 \mu \mathrm{m}$. Results are mean $\pm \operatorname{SEM}(n=3$ brains in $\boldsymbol{B}, n=3-4$ brains in $\boldsymbol{D})$.
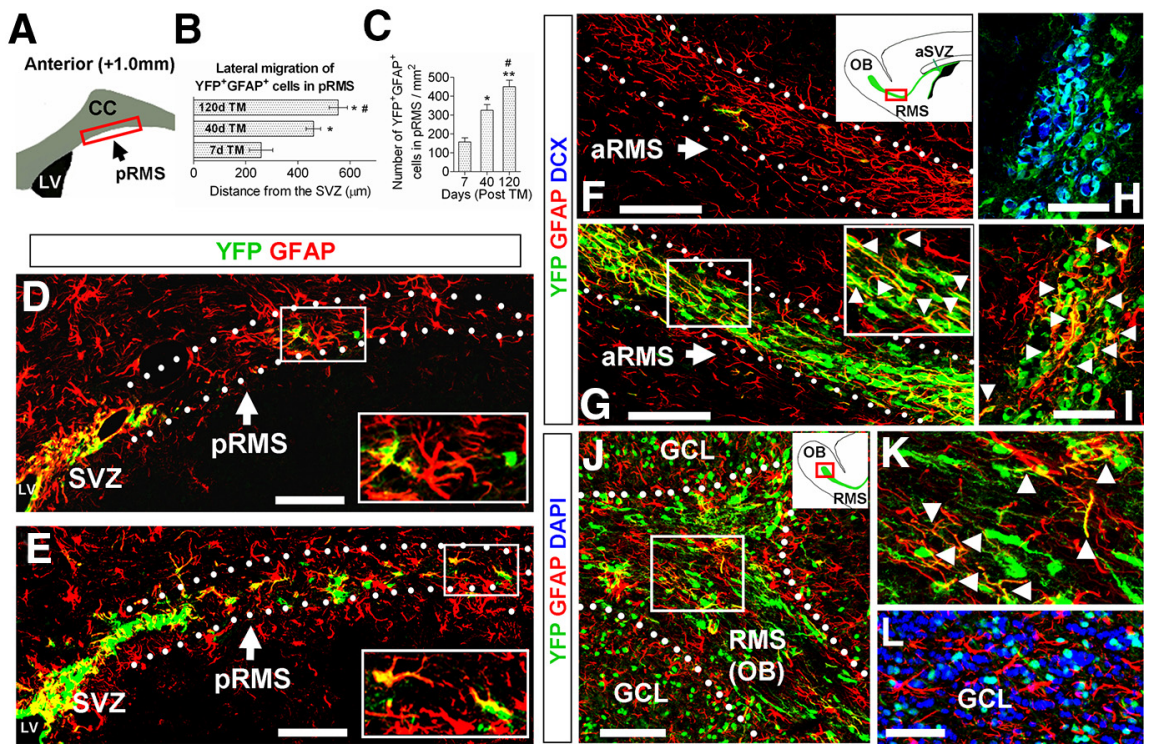

Figure 5. Nestin fate-mapping of astrocytes in the adult RMS. $\boldsymbol{A}$, Schematic representation of a coronal forebrain section $1.0 \mathrm{~mm}$ anterior to bregma used for analysis ( $\boldsymbol{B}-\boldsymbol{E})$ of the posterior RMS (pRMS). With increasing time post-TM, the density of nestin fate-mapped astrocytes (EYFP ${ }^{+} /$GFAP $\left.^{+}\right)$increased in the pRMS, as demonstrated by quantifications $(\boldsymbol{B}, \boldsymbol{C})$ and immunostaining $(\boldsymbol{D}, 7 \mathrm{~d} ; \boldsymbol{E}, 120 \mathrm{~d}$ post-TM). $\boldsymbol{F}$ - $\boldsymbol{I}$, Anterior RMS (aRMS) visualized in sagittal $(\boldsymbol{F}, \boldsymbol{G})$ and coronal $(\boldsymbol{H}, \boldsymbol{I})$ sections. Note the robust stream of SVZ-derived EYFP ${ }^{+}$ cells in RMS at 120 d post-TM $(\boldsymbol{G}-\boldsymbol{I})$. Some of the EYFP ${ }^{+}$cells were colabeled with DCX $(\boldsymbol{H})$ or GFAP $(\boldsymbol{G}, \boldsymbol{I})$. Also, note the paucity of EYFP ${ }^{+}$ cells in the aRMS at $3 \mathrm{~d}$ post-TM $(\boldsymbol{F})$, indicating that there were very few nestin ${ }^{+} \mathrm{NPC}$ in RMS, and validating the mapping strategy. $\boldsymbol{J}, \boldsymbol{K}$, RMS within the olfactory [RMS(ob)] at $120 \mathrm{~d}$ post-TM, showing some fate-mapped cells are astrocytes (EYFP ${ }^{+} / \mathrm{GFAP}^{+}$; $\boldsymbol{K}_{\text {: }}$ magnified image of the boxed area in $J$ ). $L$, EYFP ${ }^{+}$astrocytes are absent in the $G C L$ at 120 d post-TM. Insets in $\boldsymbol{D}, \boldsymbol{E}$, and $\boldsymbol{G}$ are magnified images of the boxed areas. Arrowheads in $\mathbf{G}, \boldsymbol{I}$, and $\boldsymbol{K}$ indicate fate-mapped astrocytes (EYFP ${ }^{+} / \mathrm{GFAP}^{+}$). The RMS is highlighted by dotted lines. (C, Corpus callosum; LV, lateral ventricle. Scale bars: $\boldsymbol{D}-\mathbf{G}, \mathbf{J}, 100 \mu \mathrm{m} ; \boldsymbol{H}, \mathbf{I}, \boldsymbol{L}, 50 \mu \mathrm{m}$. ${ }^{*} p<0.01$ versus $7 \mathrm{~d}, \# p<0.05$ versus $40 \mathrm{~d}$ in $\boldsymbol{B} ;{ }^{*} p<$ 0.01 versus $7 \mathrm{~d},{ }^{* *} p<0.001$ versus $7 \mathrm{~d}, \# p<0.01$ versus $40 \mathrm{~d}$ in $C$. Results are mean $\pm \mathrm{SEM}$ ( $n=3-4$ brains). 


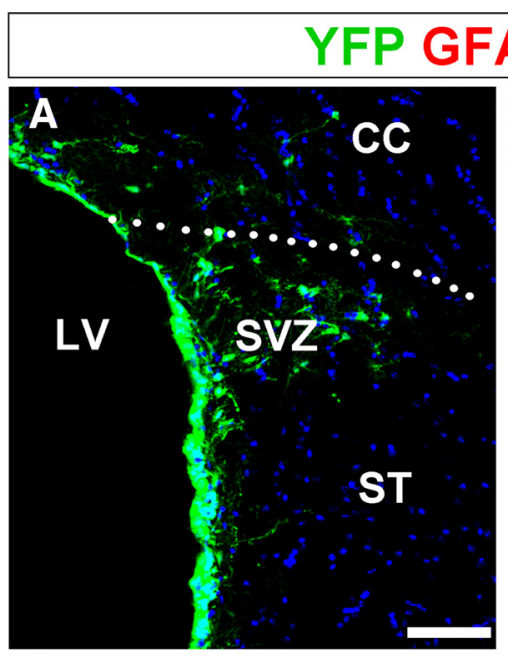

\section{AP DAPI}
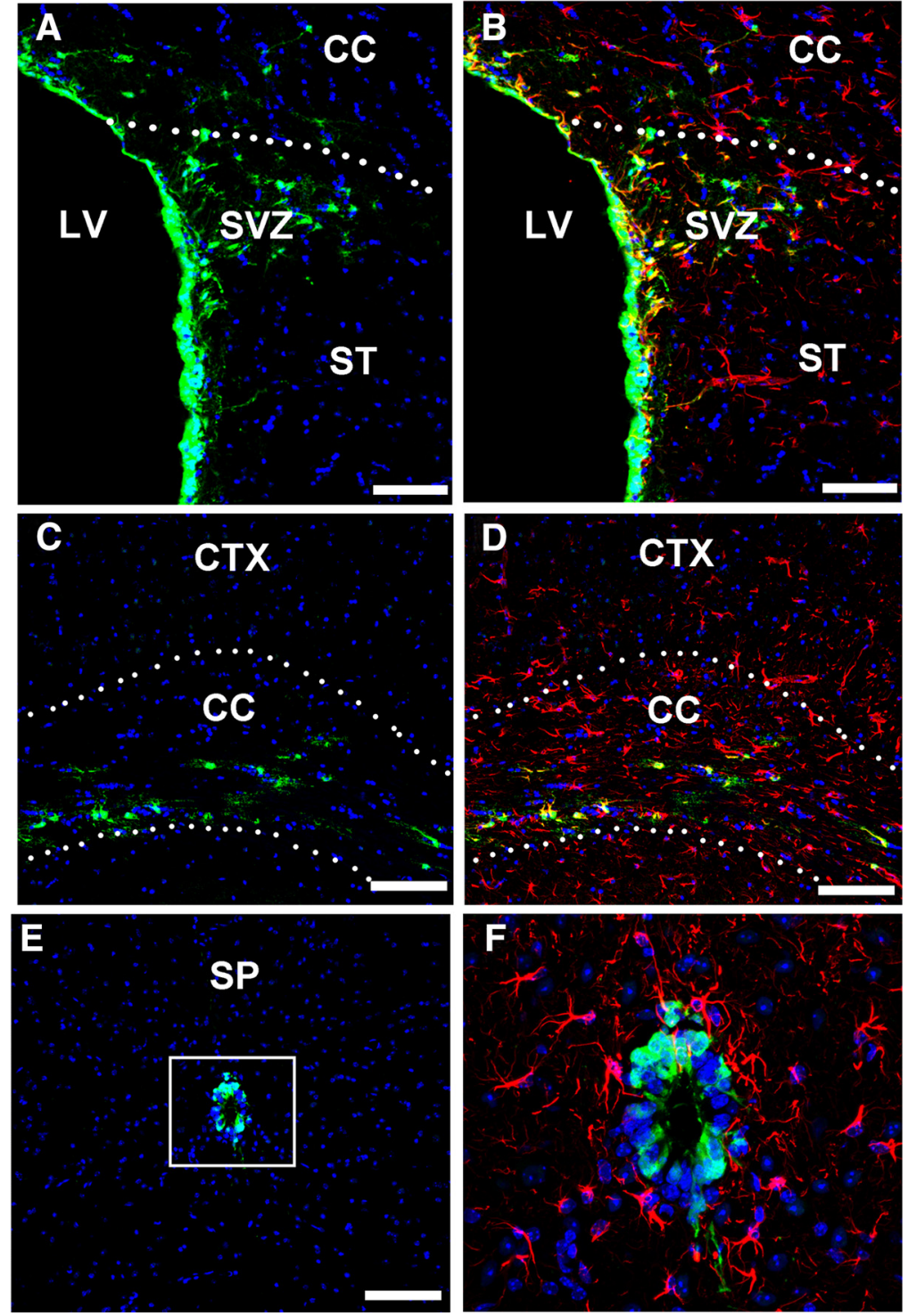

Figure 6. Absence of NSC-derived astroglial production in the forebrain gray matter and the spinal cord in normal adults. $A-D$ Low-magnification images of coronal brain sections at $270 \mathrm{~d}$ post-TM. EYFP ${ }^{+} /$GFAP $^{+}$cells migrated into the corpus callosum in both close proximity to the $\operatorname{SVZ}(\boldsymbol{A}, \boldsymbol{B})$ and distal to the $\operatorname{SVZ}(\boldsymbol{C}, \boldsymbol{D})$, but did not enter the striatum $(\boldsymbol{A}, \boldsymbol{B})$ or cortex $(\boldsymbol{C}, \boldsymbol{D})$. $\boldsymbol{E}$, The absence of EYFP ${ }^{+}$cells outside the central cannel at $270 \mathrm{~d}$ post-TM. $\boldsymbol{F}$, Higher-magnification image of the area outlined by a rectangle in $\boldsymbol{E}$ showing the lack of NSC-derived astrogliogenesis in the adult spinal cord. CC, Corpus callosum; CTX, cortex; LV, lateral ventricle; SP, spinal cord; ST, striatum. Scale bars, $100 \mu \mathrm{m}$.

2008) and our finding that a few $\mathrm{EYFP}^{+} / \mathrm{GFAP}^{+}$cells were located along the RMS at early days post-TM, we examined proliferation of $\mathrm{GFAP}^{+}$cells in the adult RMS. No Ki67 ${ }^{+} / \mathrm{GFAP}^{+}$cells were detected in the adult RMS at 3 or 7 months of age, arguing against RMS GFAP ${ }^{+}$ cells as a substantial source for new astrocyte production in the normal adult RMS

\section{Lack of nestin ${ }^{+}$NPC-derived astrogliogenesis in the} forebrain cortex and striatum, and in the spinal cord during normal adulthood

We observed no fate-mapped astrocytes (i.e., $\mathrm{EYFP}^{+} / \mathrm{GFAP}^{+}$) in the normal adult cortex or striatum (Fig. $6 A-D ; 270$ d postTM). In the normal adult spinal cord, EYFP expression was restricted to the central canal, with no fate-mapped GFAP $^{+}$ astrocytes elsewhere in the spinal cord gray or white matter (Fig. $6 E, F ; 270 \mathrm{~d}$ post-TM)

\section{Discussion}

The best documented function of nestin ${ }^{+}$ SVZ NPCs in normal adult mice is the production of neuroblasts; these migrate via the RMS to the olfactory bulb, where they contribute to olfactory learning (Sakamoto et al., 2014). SVZ NPCs also produce oligodendroglial progenitor cells after forebrain demyelination (Menn et al., 2006; Sullivan et al., 2013), and contribute, along with reactive astrocytes in gray and white matter, to forebrain astrogliosis following CNS trauma, ischemia, or inflammation (Buffo et al., 2008; Li et al., 2010; Robel et al., 2011; Benner et al., 2013). So far, evidence of SVZ astrogliogenesis in normal adults has been scant. Prior retroviral lineage tracing studies in the normal adult SVZ extending to 2-3 weeks postinjection (Doetsch et al., 1999; Menn et al., 2006) documented neuronogenesis and oligodendrogenesis, but did not specifically address astrogliogenesis. Interestingly, McCarthy and Leblond (1988) reported that, although a $2 \mathrm{~h}$ systemic ${ }^{3} \mathrm{H}$-thymidine pulse failed to label corpus callosum astrocytes in 9 month postnatal mice, $12 \%$ of the total corpus callosum astrocytes were labeled following daily systemic administration of ${ }^{3} \mathrm{H}$ thymidine for $30 \mathrm{~d}$. However, this long ${ }^{3} \mathrm{H}$-thymidine-labeling approach was not designed to discriminate between astroglial mitosis in the corpus callosum and mitotic labeling of SVZ progenitor cells that subsequently migrated into the corpus callosum.

In contrast, our long-term nestin fatemapping approach showed that the SVZ is a source for continuous astrogliogenesis in the normal adult corpus callosum. This conclusion was supported by the absence of $\mathrm{Ki}^{+}$(proliferating) fate-mapped astrocytes in the corpus callosum, and the progressive accumulation of fatemapped corpus callosum astrocytes with increasing time post-TM. These newly recruited corpus callosum astrocytes formed AQP $4^{+}$ labeled contacts with blood vessels and expressed the glutamate transporters EAAT1 and EAAT2. We did not detect any fate-mapped cells with immature astroglial features in the corpus callosum: all corpus callosum astrocytes, whether EYFP ${ }^{+}$ or $\mathrm{EYFP}^{-}$, were vimentin ${ }^{+}$and no $\mathrm{EYFP}^{+} /$vimentin $^{+} /$ $\mathrm{GFAP}^{-}$cells (immature astrocytes) were present in the corpus callosum. Furthermore, no corpus callosum $\mathrm{EYFP}^{+}$astrocytes in these normal adult mice expressed immunoreactive nestin.

Despite the progressive accumulation of $\mathrm{EYFP}^{+}$astrocytes in the corpus callosum with increasing time post-TM, overall numbers of corpus callosum astrocytes did not increase, and fate-mapped astrocytes did not migrate into the adjacent cortex or 
striatum. These observations together with the occasional corpus callosum astroglial apoptosis that we documented strongly suggest ongoing astroglial replacement in the normal adult corpus callosum. Our data (Fig. 4D) also indicate that $>10 \%$ of the corpus callosum astrocytes present in normal 3-month-old mice are replaced by SVZ-derived new astrocytes over the ensuing 9 months.

SVZ NSCs differentiate into astrocytes that, in the early postnatal period, form a glial tube within the RMS (Bonfanti and Peretto, 2007; Nityanandam et al., 2012). However, whether the SVZ continues to produce RMS astrocytes during adulthood has not been determined. Our study shows that some nestin fatemapped astrocytes, rather than entering the corpus callosum, join the astroglial latticework that outlines the RMS and guides RMS neuroblast migration (Sun et al., 2010). It has been reported that the adult murine RMS contains cells that, by their capacity to generate neurospheres when cultured with epidermal growth factor or fibroblast growth factor-2, can be classified as neural stem cells (Gritti et al., 2002). But because few $\mathrm{EYFP}^{+} / \mathrm{GFAP}^{+}$ cells were present in either posterior or anterior RMS in mice killed a week or less post-TM (Fig. $5 D, F$ ), and we saw no $\mathrm{Ki}^{+} 7^{+} / \mathrm{GFAP}^{+}$cells in the RMS at any time point, we concluded that the fate-mapped astrocytes that accumulated in the RMS at late time-points post-TM originated in the SVZ. These $\mathrm{EYFP}^{+} / \mathrm{GFAP}^{+}$astrocytes were intermingled with DCX $^{+}$neuroblasts (Fig. $5 H, I$ ). But unlike the migrating RMS neuroblasts, these fate-mapped astrocytes did not penetrate into the granule cell and periglomerular layers of the olfactory (Fig. 5L).

In summary, our data demonstrate for the first time that there is slow, ongoing recruitment of astrocytes originating from nestin $^{+}$SVZ NPCs in the normal adult mammalian forebrain. It will be interesting in future to determine the relative contributions of altered rates of SVZ astrogliogenesis and of astroglial apoptosis to forebrain reactive astrogliosis, a feature of many neurodegenerative and neuroinflammatory diseases.

\section{References}

Agrawal HC, Davis JM, Himwich WA (1968) Developmental changes in mouse brain: weight, water content and free amino acids. J Neurochem 15:917-923. CrossRef Medline

Alonso M, Ortega-Pérez I, Grubb MS, Bourgeois JP, Charneau P, Lledo PM (2008) Turning astrocytes from the rostral migratory stream into neurons: a role for the olfactory sensory organ. J Neurosci 28:11089-11102. CrossRef Medline

Alvarez-Buylla A, Kohwi M, Nguyen TM, Merkle FT (2008) The heterogeneity of adult neural stem cells and the emerging complexity of their niche. Cold Spring Harb Symp Quant Biol 73:357-365. CrossRef Medline

Bandeira F, Lent R, Herculano-Houzel S (2009) Changing numbers of neuronal and non-neuronal cells underlie postnatal brain growth in the rat. Proc Natl Acad Sci U S A 106:14108-14113. CrossRef Medline

Benner EJ, Luciano D, Jo R, Abdi K, Paez-Gonzalez P, Sheng H, Warner DS, Liu C, Eroglu C, Kuo CT (2013) Protective astrogenesis from the SVZ niche after injury is controlled by Notch modulator Thbs4. Nature 497: 369-373. CrossRef Medline

Bonfanti L, Peretto P (2007) Radial glial origin of the adult neural stem cells in the subventricular zone. Prog Neurobiol 83:24-36. CrossRef Medline

Buffo A, Rite I, Tripathi P, Lepier A, Colak D, Horn AP, Mori T, Götz M (2008) Origin and progeny of reactive gliosis: A source of multipotent cells in the injured brain. Proc Natl Acad Sci U S A 105:3581-3586. CrossRef Medline

Chaudhry FA, Lehre KP, van Lookeren Campagne M, Ottersen OP, Danbolt NC, Storm-Mathisen J (1995) Glutamate transporters in glial plasma membranes: highly differentiated localizations revealed by quantitative ultrastructural immunocytochemistry. Neuron 15:711-720. CrossRef Medline

Chuang N, Mori S, Yamamoto A, Jiang H, Ye X, Xu X, Richards LJ, Nathans J, Miller MI, Toga AW, Sidman RL, Zhang J (2011) An MRI-based atlas and database of the developing mouse brain. Neuroimage 54:80-89. CrossRef Medline

Doetsch F, Caillé I, Lim DA, García-Verdugo JM, Alvarez-Buylla A (1999) Subventricular zone astrocytes are neural stem cells in the adult mammalian brain. Cell 97:703-716. CrossRef Medline

Galou M, Colucci-Guyon E, Ensergueix D, Ridet JL, Gimenez y Ribotta M, Privat A, Babinet C, Dupouey P (1996) Disrupted glial fibrillary acidic protein network in astrocytes from vimentin knockout mice. J Cell Biol 133:853-863. CrossRef Medline

Ge WP, Miyawaki A, Gage FH, Jan YN, Jan LY (2012) Local generation of glia is a major astrocyte source in postnatal cortex. Nature 484:376-380. CrossRef Medline

Gritti A, Bonfanti L, Doetsch F, Caille I, Alvarez-Buylla A, Lim DA, Galli R, Garcia Verdugo JM, Herrera DG, Vescovi AL (2002) Multipotent neural stem cells reside into the rostral extension and olfactory bulb of adult rodents. J Neurosci 22:437-445. Medline

Johnson VL, Ko SC, Holmstrom TH, Eriksson JE, Chow SC (2000) Effector caspases are dispensable for the early nuclear morphological changes during chemical-induced apoptosis. J Cell Sci 113:2941-2953. Medline

Kálmán M, Ajtai BM (2001) A comparison of intermediate filament markers for presumptive astroglia in the developing rat neocortex: immunostaining against nestin reveals more detail, than GFAP or vimentin. Int J Dev Neurosci 19:101-108. CrossRef Medline

Lagace DC, Whitman MC, Noonan MA, Ables JL, DeCarolis NA, Arguello AA, Donovan MH, Fischer SJ, Farnbauch LA, Beech RD, DiLeone RJ, Greer CA, Mandyam CD, Eisch AJ (2007) Dynamic contribution of nestin-expressing stem cells to adult neurogenesis. J Neurosci 27:1262312629. CrossRef Medline

Levison SW, Chuang C, Abramson BJ, Goldman JE (1993) The migrational patterns and developmental fates of glial precursors in the rat subventricular zone are temporally regulated. Development 119:611-622. Medline

Li L, Harms KM, Ventura PB, Lagace DC, Eisch AJ, Cunningham LA (2010) Focal cerebral ischemia induces a multilineage cytogenic response from adult subventricular zone that is predominantly gliogenic. Glia 58:16101619. CrossRef Medline

Ling EA, Leblond CP (1973) Investigation of glial cells in semithin sections: II. Variation with age in the numbers of the various glial cell types in rat cortex and corpus callosum. J Comp Neurol 149:73-81. CrossRef Medline

McCarthy GF, Leblond CP (1988) Radioautographic evidence for slow astrocyte turnover and modest oligodendrocyte production in the corpus callosum of adult mice infused with $3 \mathrm{H}$-thymidine. J Comp Neurol 271: 589-603. CrossRef Medline

Menn B, Garcia-Verdugo JM, Yaschine C, Gonzalez-Perez O, Rowitch D, Alvarez-Buylla A (2006) Origin of oligodendrocytes in the subventricular zone of the adult brain. J Neurosci 26:7907-7918. CrossRef Medline

Molofsky AV, Krenick R, Ullian E, Tsai HH, Deneen B, Richardson WD, Barres BA, Rowitch DH (2012) Astrocytes and disease: a neurodevelopmental perspective. Genes Dev 26:891-907. CrossRef Medline

Nielsen S, Nagelhus EA, Amiry-Moghaddam M, Bourque C, Agre P, Ottersen OP (1997) Specialized membrane domains for water transport in glial cells: high-resolution immunogold cytochemistry of aquaporin-4 in rat brain. J Neurosci 17:171-180. Medline

Nityanandam A, Parthasarathy S, Tarabykin V (2012) Postnatal subventricular zone of the neocortex contributes GFAP+ cells to the rostral migratory stream under the control of Sip1. Dev Biol 366:341-356. CrossRef Medline

Pixley SK, de Vellis J (1984) Transition between immature radial glia and mature astrocytes studied with a monoclonal antibody to vimentin. Brain Res 317:201-209. Medline

Robel S, Berninger B, Götz M (2011) The stem cell potential of glia: lessons from reactive gliosis. Nat Rev Neurosci 12:88-104. CrossRef Medline

Rothstein JD, Martin L, Levey AI, Dykes-Hoberg M, Jin L, Wu D, Nash N, Kuncl RW (1994) Localization of neuronal and glial glutamate transporters. Neuron 13:713-725. CrossRef Medline 
Sakamoto M, Ieki N, Miyoshi G, Mochimaru D, Miyachi H, Imura T, Yamaguchi M, Fishell G, Mori K, Kageyama R, Imayoshi I (2014) Continuous postnatal neurogenesis contributes to formation of the olfactory bulb neural circuits and flexible olfactory associative learning. J Neurosci 34: 5788-5799. CrossRef Medline

Sauvageot CM, Stiles CD (2002) Molecular mechanisms controlling cortical gliogenesis. Curr Opin Neurobiol 12:244-249. CrossRef Medline

Schnitzer J, Franke WW, Schachner M (1981) Immunocytochemical demonstration of vimentin in astrocytes and ependymal cells of developing and adult mouse nervous system. J Cell Biol 90:435-447. CrossRef Medline

Sild M, Ruthazer ES (2011) Radial glia: progenitor, pathway, and partner. Neuroscientist 17:288-302. CrossRef Medline

Sohn J, Selvaraj V, Wakayama K, Orosco L, Lee E, Crawford SE, Guo F, Lang J, Horiuchi M, Zarbalis K, Itoh T, Deng W, Pleasure D (2012) PEDF is a novel oligodendrogenic morphogen acting on the adult SVZ and corpus callosum. J Neurosci 32:12152-12164. CrossRef Medline

Srinivas S, Watanabe T, Lin CS, William CM, Tanabe Y, Jessell TM, Costantini F (2001) Cre reporter strains produced by targeted inser- tion of EYFP and ECFP into the ROSA26 locus. BMC Dev Biol 1:4. CrossRef Medline

Sullivan GM, Mierzwa AJ, Kijpaisalratana N, Tang H, Wang Y, Song SK, Selwyn R, Armstrong RC (2013) Oligodendrocyte lineage and subventricular zone response to traumatic axonal injury in the corpus callosum. J Neuropathol Exp Neurol 72:1106-1125. CrossRef Medline

Sun W, Kim H, Moon Y (2010) Control of neuronal migration through rostral migratory stream in mice. Anat Cell Biol 43:269-279. CrossRef Medline

Suzuki SO, Goldman JE (2003) Multiple cell populations in the early postnatal subventricular zone take distinct migratory pathways: a dynamic study of glial and neuronal progenitor migration. J Neurosci 23:4240-4250. Medline

Zhuo L, Sun B, Zhang CL, Fine A, Chiu SY, Messing A (1997) Live astrocytes visualized by green fluorescent protein in transgenic mice. Dev Biol 187: 36-42. CrossRef Medline

Zimmerman L, Parr B, Lendahl U, Cunningham M, McKay R, Gavin B, Mann J, Vassileva G, McMahon A (1994) Independent regulatory elements in the nestin gene direct transgene expression to neural stem cells or muscle precursors. Neuron 12:11-24. CrossRef Medline 